\title{
ARTICLE Impaired instrumental reversal learning is associated with increased medial prefrontal cortex activity in Sapap3 knockout mouse model of compulsive behavior
}

\author{
Elizabeth E. Manning (D) $^{1,2,3}$, Alexandre Y. Dombrovski ${ }^{1,3}$, Mary M. Torregrossa ${ }^{1,2}$ and Susanne E. Ahmari ${ }^{1,2,3}$
}

\begin{abstract}
Convergent functional neuroimaging findings implicate hyperactivity across the prefrontal cortex (PFC) and striatum in the neuropathology of obsessive compulsive disorder (OCD). The impact of cortico-striatal circuit hyperactivity on executive functions subserved by these circuits is unclear, because impaired recruitment of PFC has also been observed in OCD patients during paradigms assessing cognitive flexibility. To investigate the relationship between cortico-striatal circuit disturbances and cognitive functioning relevant to OCD, Sapap3 knockout mice (KOs) and littermate controls were tested in an instrumental reversal-learning paradigm to assess cognitive flexibility. Cortical and striatal activation associated with reversal learning was assessed via quantitative analysis of expression of the immediate early gene cFos and generalized linear mixed-effects models. Sapap3-KOs displayed heterogeneous reversal-learning performance, with almost half $(n=13 / 28)$ failing to acquire the reversed contingency, while the other $15 / 28$ had similar acquisition as controls. Notably, reversal impairments were not correlated with compulsive grooming severity. cFos analysis revealed that reversal performance declined as medial PFC (mPFC) activity increased in Sapap3KOs. No such relationship was observed in controls. Our studies are among the first to describe cognitive impairments in a transgenic OCD-relevant model, and demonstrate pronounced heterogeneity among Sapap3-KOs. These findings suggest that increased neural activity in MPFC is associated with impaired reversal learning in Sapap3-KOs, providing a likely neural basis for this observed heterogeneity. The Sapap3-KO model is thus a useful tool for future mechanistic studies to determine how mPFC hyperactivity contributes to OCD-relevant cognitive dysfunction.
\end{abstract}

Neuropsychopharmacology (2019) 44:1494-1504; https://doi.org/10.1038/s41386-018-0307-2

\section{INTRODUCTION}

Obsessive compulsive disorder (OCD) is a debilitating neuropsychiatric disorder that affects $1-3 \%$ of the population, and is characterized by persistent intrusive thoughts (obsessions) and uncontrollable repetitive rituals (compulsions) [1, 2]. There is a remarkable convergence of abnormal functional neuroimaging findings in prefrontal cortex (PFC)-striatal circuits in OCD patients [3]; however, there are discrepancies in the directionality of these results [4]. Typically, hyperactivity has been reported at baseline and during symptom provocation in OCD patients in areas including orbitofrontal cortex (OFC) [5-7], anterior-cingulate cortex (ACC) [6, 7], ventromedial PFC (vmPFC) [8], and caudate $[5,7]$; this activity is normalized following successful treatment [9, 10]. In contrast, prefrontal regions including OFC [11, 12], vmPFC [13-16], and dorsolateral PFC (DLPFC) [11, 17] display impaired recruitment by cognitive demands. Alterations in resting-state functional connectivity in PFC-striatal circuits have also been described, but both increases [18] and decreases [19] have been reported. Together, these findings suggest complex changes in PFC-striatal functioning in OCD patients, which may represent a valuable target for future therapeutic interventions.

Precise neural circuit mechanisms underlying these disturbances are difficult to uncover in clinical studies, and preclinical models have become an increasingly valuable complementary tool. A growing number of reports describe OCD-relevant transgenic mouse models, with a particular focus on the phenotype of compulsive grooming [20-25]. This is an ethologically relevant compulsive behavior in mice [26], which shows predictive validity using clinically effective serotonin-reuptake inhibitors in several different models [20, 22, 24, 27]. While this research has yielded important insights regarding striatal alterations that contribute to compulsive grooming $[20,21,25,28]$, there has been little exploration of translational OCD-relevant cognitive paradigms in these experimental mouse systems. To our knowledge, the present study is among the first to describe cognitive impairments in an OCD-relevant mouse model [29], and identify potential underlying neural substrates in the PFC and striatum.

To probe the neural circuits underlying cognitive flexibility, we examined Sapap3 knockout mice (KOs), the most widely used preclinical model in OCD research [20, 21, 28]. Sapap genes encode a family of four postsynaptic density-scaffolding proteins, and Sapap1 and Sapap3 are both candidates for OCD risk [30, 31]. Sapap3-KOs show compulsive grooming that is reversed by the first-line OCD treatment fluoxetine, and several studies have demonstrated dorsal striatal hyperactivity in this model $[20,21$,

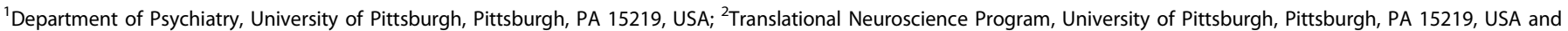
${ }^{3}$ Center for Neural Basis of Cognition, University of Pittsburgh, Pittsburgh, PA 15219, USA
}

Correspondence: Susanne E. Ahmari (ahmarise@upmc.edu) 
28]. The goal of this study was to determine whether Sapap3-KOs show OCD-relevant cognitive impairment, and assess functioning of associated PFC and striatal areas. OCD patients reliably show performance deficits and/or altered blood oxygen leveldependent (BOLD) responses during reversal-learning paradigms $[11,12,32,33]$, and impaired reversal learning may reflect circuit dysfunction that could contribute to perseverative thoughts and actions [33]. We therefore used a reversal-learning paradigm to examine cognitive flexibility in Sapap3-KOs and wild-type (WT) littermates, and quantitative cFos analysis to determine if activity in PFC and striatal regions was differentially associated with reversal performance in Sapap3-KOs.

\section{MATERIALS AND METHODS}

Animals

Sapap3-KOs and WT littermates were maintained on C57BL/6 background, and were derived from a colony initially established at MIT by Dr. Guoping Feng [20]. Mice were group-housed with 2-5 same-sex mice per cage and ad libitum access to food and water until operant training commenced between 5 and 7 months of age (further details about cohorts available in figure legends and Supplementary Materials). At least 12 days prior to commencement of operant training, mice were transferred to a reverse lightcycle room (12:12, lights on at 7:00 pm). All experiments were approved by the Institutional Animal Care and Use Committee at the University of Pittsburgh in compliance with National Institutes of Health guidelines for the care and use of laboratory animals.

\section{Reversal learning: behavioral characterization}

Mice were tested in a reversal-learning paradigm similar to that previously described [34]. Briefly, mice were tested in operant chambers (Med Associates, Fairfax, VT) with two levers positioned either side of a food magazine. Mice were trained to acquire lever pressing for food rewards (20-mg chocolate-flavored grain-based pellets; BioServ, Flemington, NJ) on a fixed-ratio 1 (FR1) schedule during hour-long sessions until they reached a criterion of 20 correct responses (see Fig. 1a for training timeline). Next, they were trained for 6 days with the same lever designated correct on variable ratio 2 (VR2) schedule (30-min sessions, "discrimination training"). Lever contingencies were then reversed for 5 days ("reversal"), before changing back to the original contingency for 5 more days ("2 ${ }^{\text {nd }}$ reversal", 30-min sessions, VR2 schedule). The criterion for successful reversal was pre-specified at $>20$ correct responses on at least 1 day of training. Supplementary Materials include further details.

\section{Reversal learning: cFos analysis}

Operant training for cohort 4 was similar to cohorts 1-3. However, in order to end the experiment on the same day for all animals for the purpose of consistent tissue collection, we stopped training mice once they reached lever training criterion to allow mice that were slower to reach the same level of performance (all pauses in training were $<7$ days; see Fig. 3a for training timeline). Once all mice reached criterion, they had 1 day of "catch-up" training on FR1 (20 correct responses maximum) before initiation of VR2 discrimination training the next day. Following a total of 6 days of discrimination, only 1 day of reversal training was performed prior to sacrifice and tissue collection (30-min session; early termination if mice earned 25 pellets). Mice that earned less than 25 pellets were given free access to the remaining pellets immediately after the session. All mice therefore consumed 25 pellets in total, minimizing the influence of total pellet consumption on cFos activation. More details available in Supplementary Materials.

Tissue collection, immunohistochemistry, and analysis

Mice were deeply anesthetized with ketamine $2 \mathrm{~h}$ after the beginning of reversal testing, and transcardially perfused with $4 \%$ paraformaldehyde (PFA; Sigma Aldrich, St Louis, MO) in $0.1 \mathrm{M}$ phosphate-buffered saline (PBS). cFos was detected using Millipore $A B E-457$ primary antibody (1:5000; Burlington, MA) and diaminobenzidine (DAB) kit (Vector Laboratories, Burlingame, $C A$ ) using standard protocols; see Supplementary Materials for further details.

Stained sections were imaged using an Olympus inverted slide scanning microscope (Olympus, Tokyo, Japan; 20x magnification, 4.6-ms exposure time), and automated cell counting was performed using CellSense software (Olympus). Ten cortical and striatal regions of interest (ROIs) were analyzed: medial and lateral OFC (mOFC and IOFC); prelimbic (PrL) and infralimbic (IL) regions of medial PFC (mPFC); dorsomedial, dorsolateral, centromedial, and ventromedial striatum (DMS, DLS, CMS, and VMS); and nucleus accumbens core (NACC) and shell (NACS). Three sections per animal spaced $\sim 210 \mu \mathrm{m}$ apart were analyzed bilaterally for each ROI for cFos counts (except for VMS-two sections). Cells were automatically detected in a $300 \times 300 \mu \mathrm{m}$ area in each ROI, using pixel intensity threshold (red: 111-256, green: $0-175$, and blue: $0-120)$ and minimum area of super-threshold filter $(9 \mu \mathrm{m})$ to detect cFos + cells.

\section{Statistical analysis}

Repeated measures ANOVAs were used to test effects of genotype and training day during each phase of operant training, with Bonferroni-corrected post hoc tests if significant interactions were detected. Unpaired nonparametric Mann-Whitney tests were used to assess genotype differences on non-repeated measures that failed normality testing (acquisition of lever pressing; compulsive grooming severity; total number of inactive lever presses). For cFos analysis, repeated measures ANOVA was used to compare the effect of genotype across the brain regions, and Spearman's rho $(\rho)$ was used to correlate cFos levels between ROls. To compare cFos measurements associated with reversal performance, a generalized linear mixed-effects (GLME) model was developed using experimental data (c-fos data and time stamps of operant responses from cohort 4). Using this model, we were able to estimate whether response rate was influenced by interactions between cFos expression and genotype in either a response type (correct/incorrect) or time (during testing)-dependent manner (response rate $\sim R O I$ cFos $x$ genotype x response type [correct/incorrect] or time); details of analysis can be found in Supplementary Material. Unlike standard correlations which are often used to compare cFos expression to behavior, GLME has key advantages including: (1) direct modeling of the effect of genotype on the cFos-behavior relationship; (2) modeling within-subject variance (e.g., mice with high vs. low variability in response rate), which improves power by increasing the degrees of freedom; and (3) modeling the effects of time and response type (correct/incorrect), which are both critical factors in reversal learning.

Statistical analyses were completed using GraphPad Prism 6 software, except for GLME analyses, which were completed in $\mathrm{R}$ (version 3.3.3; package: stats:glm; link to code in Supplementary Materials). While cFos + cell density was intercorrelated across regions (Figure S1), we did not perform dimension reduction in order to avoid assumptions about the determinants of these relationships. Instead, we adopted the conservative family-wise type I error control strategy for GLME, applying the Bonferroni correction for 10 regions ( $P$ was considered significant when $<0.005)$. Graphs show mean \pm standard error of the mean (SEM) unless otherwise stated. For graphs of GLME analysis, post hoc contrasts used Tukey adjustments to determine the genotype and response type accounting for observed three-way statistical interactions; see figure legend for more details. 
A

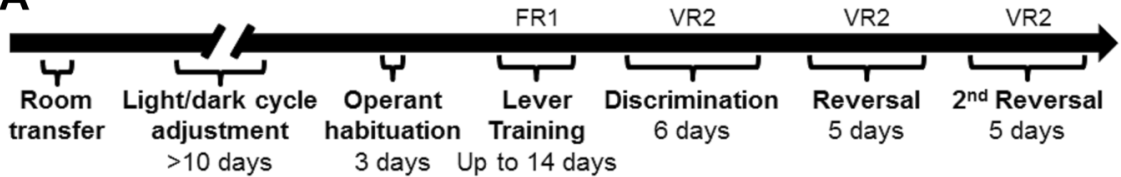

B

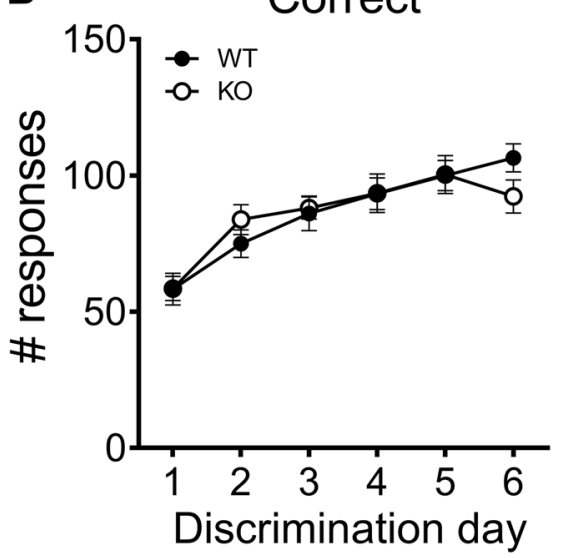

D

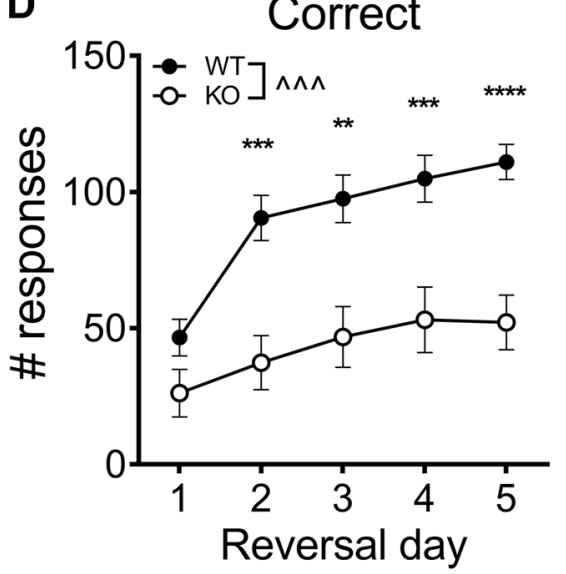

C

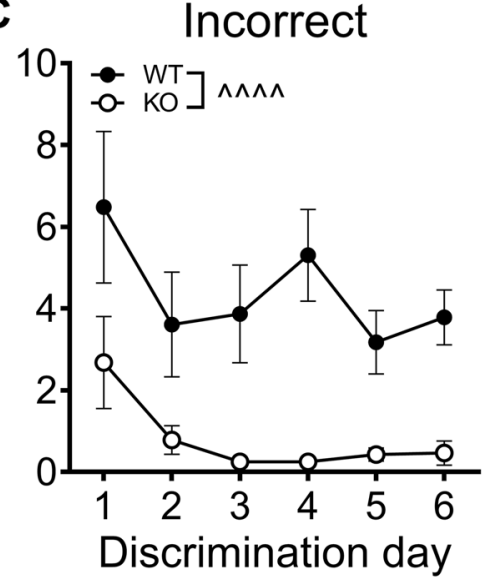

E

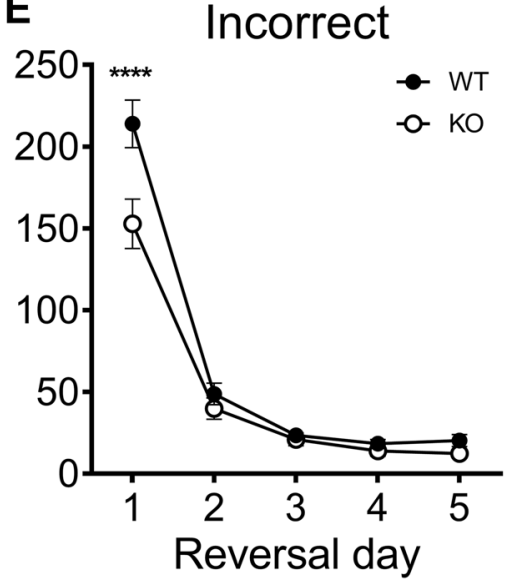

Fig. 1 Sapap3-KOs show impaired reversal learning. a Timeline of operant training. b Following acquisition of lever training criteria, Sapap3KOs showed normal levels of correct responding, although incorrect responses were lower than WT (c). d Following reversal, Sapap3-KOs showed impaired correct-response acquisition. e Perseverative responding on the previously correct lever was also lower in KOs, but only on the first day of training. $\wedge$ denotes $P$-value of the main effect, whereas ${ }^{*}$ denotes $P$-value of post hoc tests comparing genotypes on each training day surviving the Bonferroni correction. $n=23 \mathrm{WT}, 28 \mathrm{KO} .{ }^{* *} P<0.01, * * * \wedge \wedge \wedge P<0.001, * * * * / \wedge \wedge \wedge \wedge P<0.0001$. FR1 fixed-ratio one schedule of reinforcement, VR2 variable ratio 2 schedule, WT wild-type controls, KO Sapap3 knockout mice

\section{RESULTS}

Impaired reversal learning in Sapap3 knockout mice Cognitive flexibility was examined in male Sapap3-KOs and WT controls, using a reversal-learning paradigm (Fig. 1a). Mice were first trained to acquire lever pressing; Sapap3-KOs showed a significant delay in acquisition (Figure S2A, median days: $\mathrm{WT}=3$, $\mathrm{KO}=5 ; \quad \mathrm{U}=156 ; \quad P=0.0011)$. However, once mice attained criterion, WTs and KOs showed similar levels of correct responding throughout 6 days of discrimination training (Fig. 1b, training day main effect: $P<0.0001, \mathrm{~F}_{5,245}=31.3$; genotype main effect: $P=$ 0.95; no interaction). Interestingly, incorrect responses were lower in Sapap3-KOs compared with WT (Fig. 1c; genotype main effect: $P<0.0001, F_{1,49}=19.5$; training day main effect: $P=0.001$, $\mathrm{F}_{5,245}=4.1$; no interaction). Decrease in incorrect responses is consistent with reports of general locomotor hypoactivity in Sapap3-KOs (Figure S3 and Ref. [29]). In Sapap3-KOs, similar rate of correct responses combined with reduced rate of incorrect responses is reflected by higher percentage of correct responses during discrimination training relative to WTs (Figure S4A).
Upon rule reversal, Sapap3-KOs showed significant impairment in acquisition of the new contingency relative to WTs (Fig. 1d; correct responses, genotype main effect: $P=0.0002, \mathrm{~F}_{1,49}=15.8$; training day main effect: $P<0.0001, \mathrm{~F}_{4,196}=24.8$; interaction: $P=$ $0.002, F_{4,196}=4.3$ ). While post hoc tests indicate that the genotypes did not differ on the first day of reversal, Sapap3-KOs showed significantly impaired performance across days 2-5. Sapap3-KOs also showed fewer perseverative responses on the previously correct lever on the first day of reversal, consistent with discrimination training (Fig. 1e; genotype main effect: $P=0.006$, $\mathrm{F}_{1,49}=8.2$; training day main effect: $P<0.0001, F_{4,196}=194.6$; interaction $P=0.0002, \mathrm{~F}_{4,196}=5.8$ ).

Sapap3-KOs show heterogeneous reversal performance Careful inspection of the data for individual differences suggested the presence of two populations within the $\mathrm{KOs}$-one that acquired rule reversal, and one that failed to do so (Fig. 2a; also see Figure S5 for a histogram of the distribution of correct responses by genotype). Using the prespecified criterion of 20 

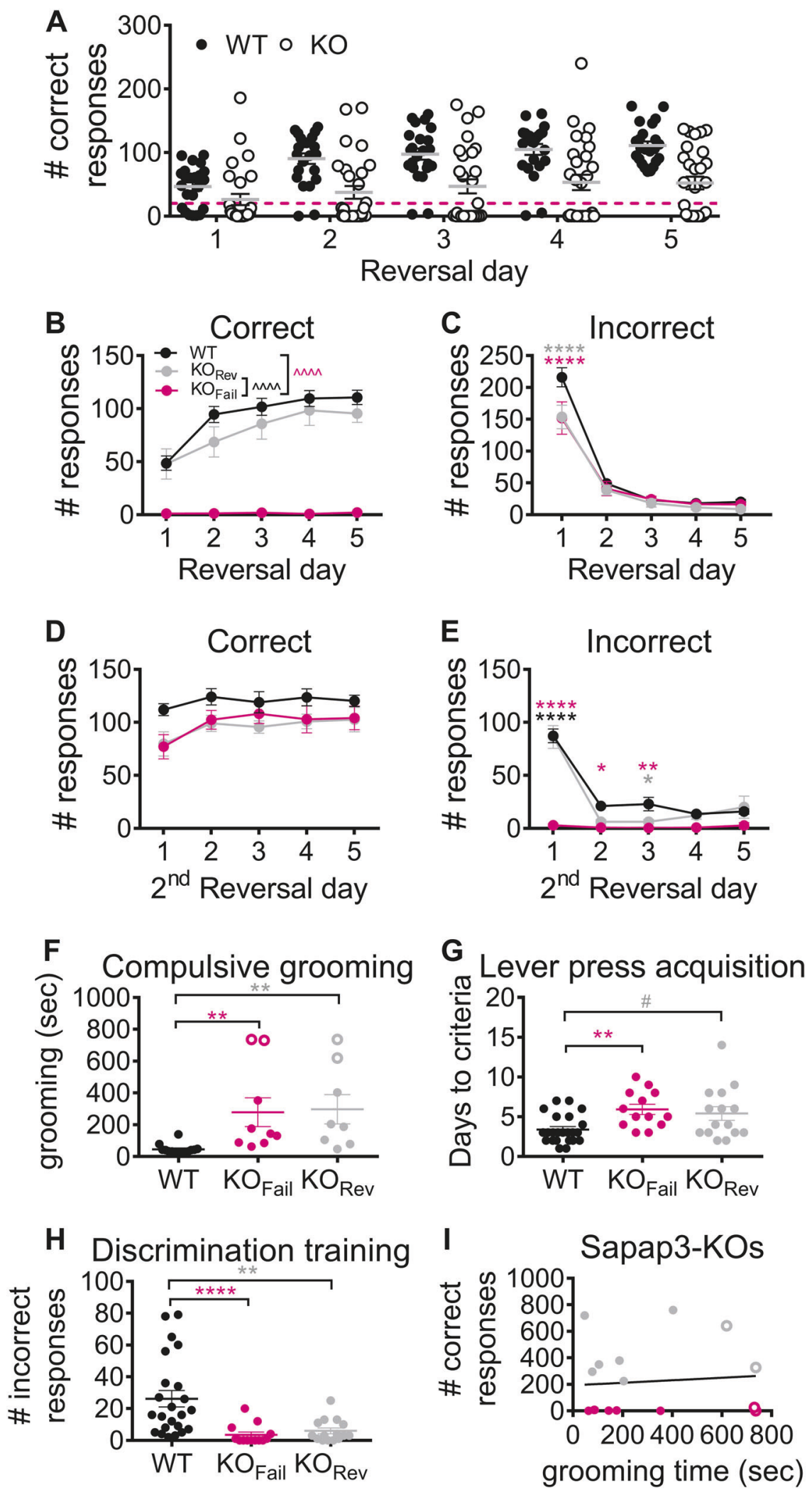

correct responses during at least one session across 5 days of reversal training (dotted line: Fig. 2a), 13/28 KOs failed reversal $\left(\mathrm{KO}_{\text {Fail }}\right)$. In contrast, no WT mice failed reversal after 5 days of training, with 16 reaching criterion on day 1,5 on day 2 , and 2 on day 5 . A descriptive follow-up analysis demonstrated that KOs that

successfully reversed $\left(\mathrm{KO}_{\mathrm{Rev}}\right)$ and WT have indistinguishable correct responses following reversal (Fig. 2b; group $x$ training day interaction: $P<0.0001, \mathrm{~F}_{2,47}=43.0$ ). However, $\mathrm{KO}_{\mathrm{Rev}}$ and $\mathrm{KO}_{\text {Fail }}$ did not differ on incorrect responses, with both groups showing lower perseverative pressing on the previously correct lever than WT on 
Fig. 2 Almost half of Sapap3-KOs show complete failure of reversal. a Sapap3-KOs can be segregated into two populations based on reversal performance. Sapap3-KOs that did not achieve more than 20 correct responses on any day of training (pink dotted line in a) were classified as failing reversal based on prespecified criteria $\left(\mathrm{KO}_{\mathrm{Fail}}\right)$. b Sapap3-KOs that reached this criterion $\left(\mathrm{KO}_{\mathrm{Rev}}\right)$ did not differ from WTs in rate of acquisition of the new correct response. c All Sapap3-KOs showed lower perseverative (incorrect) responses on day 1 (Bonferroni-corrected post hoc test day 1: WT vs. $\mathrm{KO}_{\text {Rev }}: \mathrm{t}_{240}=4.6$; WT vs. $\mathrm{KO}_{\text {Fail: }} \mathrm{t}_{240}=4.5 ; \mathrm{KO}_{\text {Rev }}$ vs. $\mathrm{KO}_{\text {Fail }}: \mathrm{t}_{240}=0.1$; all other days not significant). $\mathbf{d}$, e Following 5 days of reversal 1, the lever contingency was returned to that used during discrimination training (2nd reversal). $\mathbf{d}$ KO $\mathrm{Fail}$ did not differ from $\mathrm{KO}_{\mathrm{Rev}}$ in correct responding during the 2 nd reversal, implying similar levels of response vigor between these two subgroups. e $\mathrm{KO}_{\mathrm{Fail}}$ showed minimal incorrect responding throughout the 2 nd reversal, and $\mathrm{KO}_{\mathrm{Rev}}$ showed fewer incorrect responses than WT on day 3 only (Bonferroni post hoc test day 3: WT vs. $\mathrm{KO}_{\text {Rev }} \mathrm{t}_{235}=2.5 ; \mathrm{WT}$ vs. $\mathrm{KO}_{\text {Fail }} \mathrm{t}_{235}=3.2 ; \mathrm{KO}_{\text {Rev }}$ vs. $\mathrm{KO}_{\text {Fail }} \mathrm{t}_{235}=0.8$ ). Although Sapap3-KOs showed increased compulsive grooming (f), delayed acquisition of lever pressing (g), and reduced inactive lever pressing during discrimination (h) relative to WT controls, this did not differ between $\mathrm{KO}_{\text {Fail }} \mathrm{Vs} \mathrm{KO}_{\text {Rev }}$. i Severity of compulsive grooming and reversal performance (total \# correct responses across 5 days of reversal training) were unrelated in Sapap3-KOs. Unfilled circles in panels $\mathbf{f}$ and $\mathbf{i}$ reflect mice that were identified as having severe lesions; filled circles denote mice that did not have lesions. $\wedge$ denotes $P$-value of the main effect, whereas $*$ denotes $P$-value of post hoc tests comparing groups on each training day surviving the Bonferroni correction. Colors of symbols denote $P$-values for post hoc tests for WT vs. $\mathrm{KO}_{\text {Fail }}$ (pink); WT vs. $\mathrm{KO}_{\text {Rev }}$ (gray); or $\mathrm{KO}_{\text {Rev }}$ vs. $\mathrm{KO}_{\text {Fail }}$ (black) surviving the Bonferroni correction. For panels a-g, $n=23 \mathrm{WT}, 28 \mathrm{KO}(13 \mathrm{KO}$ Fail); for panel $\mathbf{h}, n=14 \mathrm{WT}, 17 \mathrm{KO}\left(9 \mathrm{KO}_{\text {Fail }}\right)$; for panel $\mathbf{i}, n=17 \mathrm{KO}$. ${ }^{*} P<0.05,{ }^{\#} P<0.10,{ }^{* *} P<0.01,{ }^{* * *} P<0.001,{ }^{* * *} / \wedge \wedge \wedge \wedge P<0.0001$. WT wild-type controls, KO Sapap3 knockout mice, $\mathrm{KO}_{\text {Fail }}$ Sapap3 knockout mice that fail to reach reversal criteria, $\mathrm{KO}_{\mathrm{Rev}} \mathrm{Sapap} 3 \mathrm{knockouts}$ that reach reversal criteria

the first day of reversal (Fig. $2 \mathrm{c}$; group $\mathrm{x}$ training day interaction: $P=0.005, \mathrm{~F}_{8,192}=2.9$; see legend for post hoc tests). WT and $\mathrm{KO}_{\mathrm{Rev}}$ made a similar number of responses before they reached reversal criterion (Figure S6). Comparing the total number of responses made by $\mathrm{KO}_{\text {Fail }}$ across 5 days of training to responses to criterion in the other groups suggests that $\mathrm{KO}_{\text {Fail }}$ performed a sufficient number of responses to acquire the new rule. Reversal learning was similarly impaired in female Sapap3-KOs (Figure S7).

After 5 days of reversal training, total lever pressing was very low in $\mathrm{KO}_{\text {Fail }}$ (5th day: correct response $=2.2 \pm 1.3$; incorrect response $=16.3 \pm 4.5$ ) compared with an average of $>100$ total responses in $\mathrm{WT}$ and $\mathrm{KO}_{\text {Rev, }}$ suggesting that the failure to reverse could be a consequence of reduced motivation or vigor. To test this possibility, a second reversal was performed with the levers returned to their original contingencies. $\mathrm{KO}_{\text {Fail }}$ and $\mathrm{KO}_{\mathrm{Rev}}$ were indistinguishable in their reacquisition of the original discrimination rule, suggesting similar levels of response vigor (Fig. 2d; group main effect: $P=0.02, F_{2,47}=4.2$; training day main effect: $P=0.0007, \mathrm{~F}_{4,188}=5.0$; no interaction). Incorrect responses on the original contingency were negligible in $\mathrm{KO}_{\text {Fail, }}$ and $\mathrm{KO}_{\mathrm{Rev}}$ showed less incorrect responding than WT on day 3 of the second reversal (Fig. 2e; group main effect: $P<0.0001$, $\mathrm{F}_{2,47}=25.9$; training day main effect: $P<0.0001, \mathrm{~F}_{4,188}=72.8$; interaction: $P<0.0001, F_{8,188}=16.5$; see legend for post hoc tests).

Other behavioral measures do not account for success or failure of Sapap3-KOs in reversal learning

Compared with WT, Sapap3-KOs showed delayed acquisition of initial lever pressing, less incorrect responding during discrimination training (Figure S2), and increased grooming. To determine whether these factors could help distinguish $\mathrm{KO}_{\mathrm{Rev}}$ and $\mathrm{KO}_{\text {Fail, }}$ data were reanalyzed based on reversal outcomes; however, KO reversal performance was not correlated with differences in any of these behaviors (Fig. 2f-i; correlation between grooming and reversal performance: $\mathrm{R}=0.09, P=0.73$; correlation between lever press acquisition and reversal performance: $\mathrm{R}=-0.17, P=0.38$; correlation between incorrect responses during discrimination and reversal performance: $\mathrm{R}=0.20, P=0.30$ ).

To determine whether genetic or environmental litter effects were contributing to reversal failure, concordance of reversal phenotype between mice with the same parents (either littermates or different litters from the same breeding pair) was analyzed in 17/28 male KOs (note: remaining $11 \mathrm{KOs}$ had no comparators since they were the only ones from a breeding pair tested in reversal). No evidence for litter/breeding pair effects on reversal performance were observed, with 10/17 mice showing discordance for reversal performance.
Altered relationship between neural activity and reversal performance in Sapap3-KOs

To examine relationships between neural activity and reversal learning in Sapap3-KOs and WTs, brains were collected $2 \mathrm{~h}$ after commencement of training on day 1 of reversal to assess cFos expression related to reversal learning (Fig. 3a). Four cortical and six striatal subregions of interest were analyzed (Fig. 3b). Repeated measures ANOVA comparing regional activity between genotypes revealed no significant differences between KOs and WTs ( $P=$ $\left.0.88, \mathrm{~F}_{1,21}=0.023\right)$, and no region $\mathrm{x}$ genotype interactions $(P=$ $0.32, F_{9,189}=1.17$, Fig. 3c). Correlated cFos density was calculated for all pairs of ROls in each genotype (Fig. 3d). This analysis revealed significantly increased correlations between ROls in KOs relative to WTs (paired $t$ test of $\rho$ values for Spearman's correlations: $t_{44}=7.3, P=4.1 \times 10^{-9}$, mean difference in $\rho=$ 0.23 ), which may reflect stronger functional connectivity [35]. Total number of correct responses did not differ between genotypes on the first day of training; however, the temporal profile of correct and incorrect responses was altered in KOs (Figure S8).

GLME was used to investigate how genotype moderated the relationship between neural activation in the ROls (cFos density) and reversal performance; all ROI effects from GLME are described in Table S1. In two prefrontal regions ( $\mathrm{PrL}$ and IL), increased cFos was associated with poor reversal learning in Sapap3-KOs (Fig. 4a, b; response rate $\sim$ genotype $\mathrm{x}$ response type $\mathrm{xOI}$ : $\mathrm{PrL}: P=0.0008$; IL: $\left.P=1.9 \times 10^{-7}\right)$. Specifically, increased cFos in PrL and IL was associated with fewer correct responses in Sapap3-KOs, whereas low c-fos densities were associated with comparable response rates in KOs and WTs. Furthermore, within Sapap3-KOs, increased cFos in PrL and IL was associated with increased perseverative incorrect responses, whereas at low cFos density Sapap3-KOs perseverated less than WTs. Differential effects of genotype were also observed in the influence of mOFC cFos between response types (Fig. $4 \mathrm{C}$; response rate $\sim$ genotype $\mathrm{x}$ response type $\mathrm{x}$ ROI: mOFC: $P=0.0007)$. Both WT and KO mice showed reduced correct responding with increasing cFos, although high cFos was associated with significantly lower correct responding in Sapap3KOs relative to WTs. In WTs, only high cFos in mOFC was also associated with reduced incorrect responses.

Changes in the combined rate of correct and incorrect responses across the first day of reversal training primarily reflect the initial burst of high-rate perseverative responding (i.e., the "extinction burst") [36], which typically decays over 30 min after initiation of extinction (Fig. 5a, also Figure S8C, D). Thus, successful extinction manifests in lower response rates late in the testing session. Genotype-dependent associations between response rate changes across the session and $\mathrm{ROI}$ cFos were observed in mOFC, PrL, IL, and NAc (Fig. 5b-f; response rate $\sim$ genotype $x$ time 


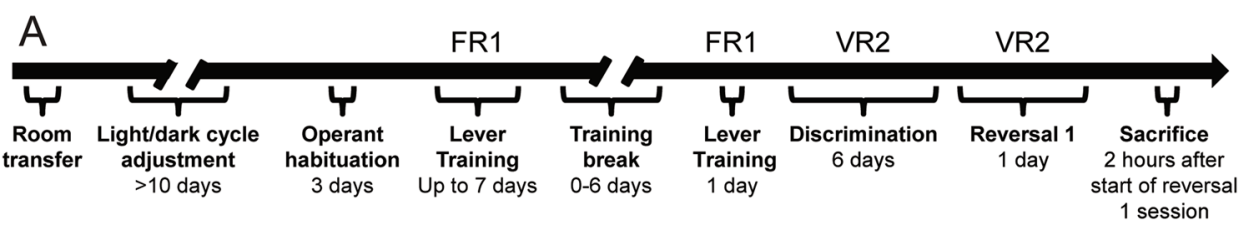

B

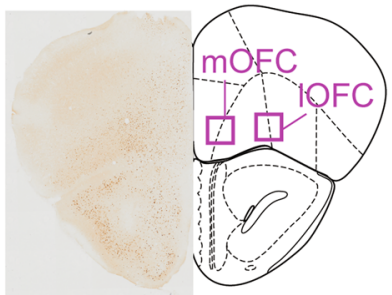

Bregma $2.80 \mathrm{~mm}$

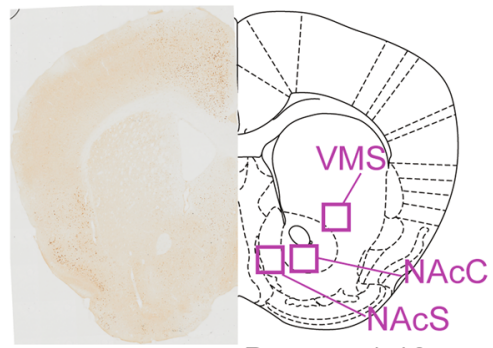

Bregma $1.10 \mathrm{~mm}$

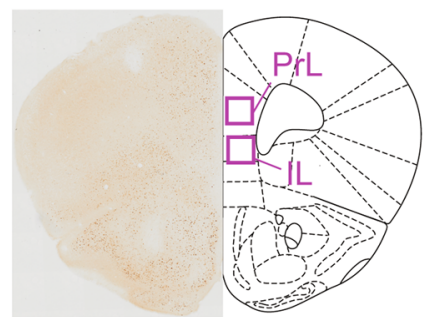

Bregma $1.98 \mathrm{~mm}$

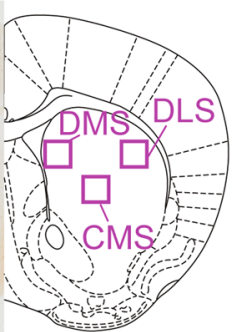

Bregma $0.74 \mathrm{~mm}$

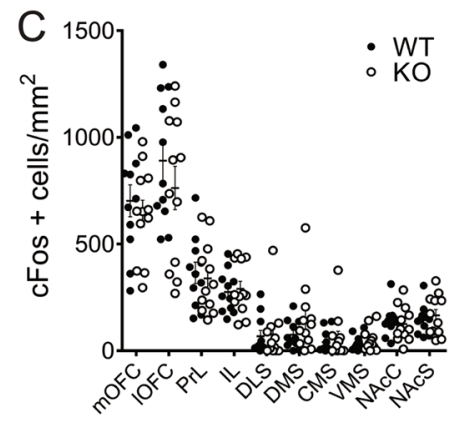

Region of interest (ROI)

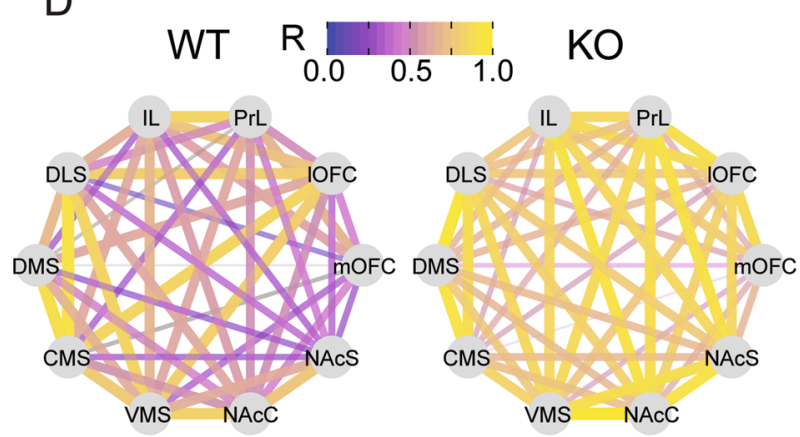

Fig. 3 Increased correlation of regional cFos expression in Sapap3-KOs following reversal. a Mice were trained in reversal learning according to an experimental timeline similar to the previous experiment, and brains were collected 120 min after commencement of training on Day 1 of reversal to assess expression of the immediate early gene cFos. $\mathbf{b}$ cFos was quantified in 10 cortical and striatal regions of interest (ROIs); left of each panel shows representative staining and right of each panel shows schematic brain atlas image with ROls highlighted. c The density of cFos- positive cells did not differ between genotypes in any of the regions assessed. d Rho $(\rho)$ values of pairwise Spearman's correlations between ROI cFos measurements were elevated in KO mice, suggesting strengthened connectivity (paired $t$ test of $\rho$ values for correlations: $\mathrm{t}_{44}=7.3, P=4.1 \times 10^{-9}$, mean difference in $\rho=0.23$ ). $n=11 \mathrm{WT}, 12 \mathrm{KO}$. FR1 fixed-ratio one schedule of reinforcement, VR2 variable ratio 2 schedule, mOFC medial orbitofrontal cortex, IOFC lateral orbitofrontal cortex, PrL prelimbic prefrontal cortex, IL infralimbic prefrontal cortex, DLS dorsolateral striatum, DMS dorsomedial striatum, CMS centromedial striatum, VMS ventromedial striatum, NAcS nucleus accumbens shell, NAcC nucleus accumbens core, WT wild-type controls, KO Sapap3 knockout mice

x ROI: mOFC: $P=3.7 \times 10^{-6}$; PrL: $P=0.001 ; \mathrm{IL}: P=0.001$; NAcC: $P=1.4 \times 10^{-5} ;$ NACS: $P=8.3 \times 10^{-5}$ ). The significant interaction term derived from the GLME is graphically represented by plotting the predicted output (response rate) of the model across a spread of typical cFos densities and timepoints that are inputted into the GLME model (Fig. 5). For example, in Fig. 5c, for two WT mice with high and low PrL cFos, respectively, the GLME model predicts that their response rate is comparable early in the session, but deviates in the middle and late timepoints of testing, with high PrL cFos associated with better extinction. This pattern is not seen in Sapap3-KOs, in which different PrL cFos levels do not predict different response rates at any timepoint during testing. Across the significant ROls, a similar pattern emerged. In WT, higher levels of cFos were associated with reduced responding late in the testing session, consistent with activity associated with successful extinction. In Sapap3-KOs, the temporal profile of recruitment of these areas was reversed, with increased cFos in IL and NAcC/S associated with reduced perseveration early in testing.

\section{DISCUSSION}

These studies demonstrate that Sapap3-KO mice, the most widely used and well-validated transgenic model in preclinical OCD research, show impairments in OCD-relevant cognitive flexibility using an instrumental reversal-learning paradigm. There was striking heterogeneity in this effect. Almost $50 \%$ of Sapap3-KOs completely failed to acquire a reversed contingency, while the other half were indistinguishable from controls in reversal acquisition. To interrogate neural correlates of this heterogeneity, we used quantitative cFos analysis in PFC-striatal circuits to assess 

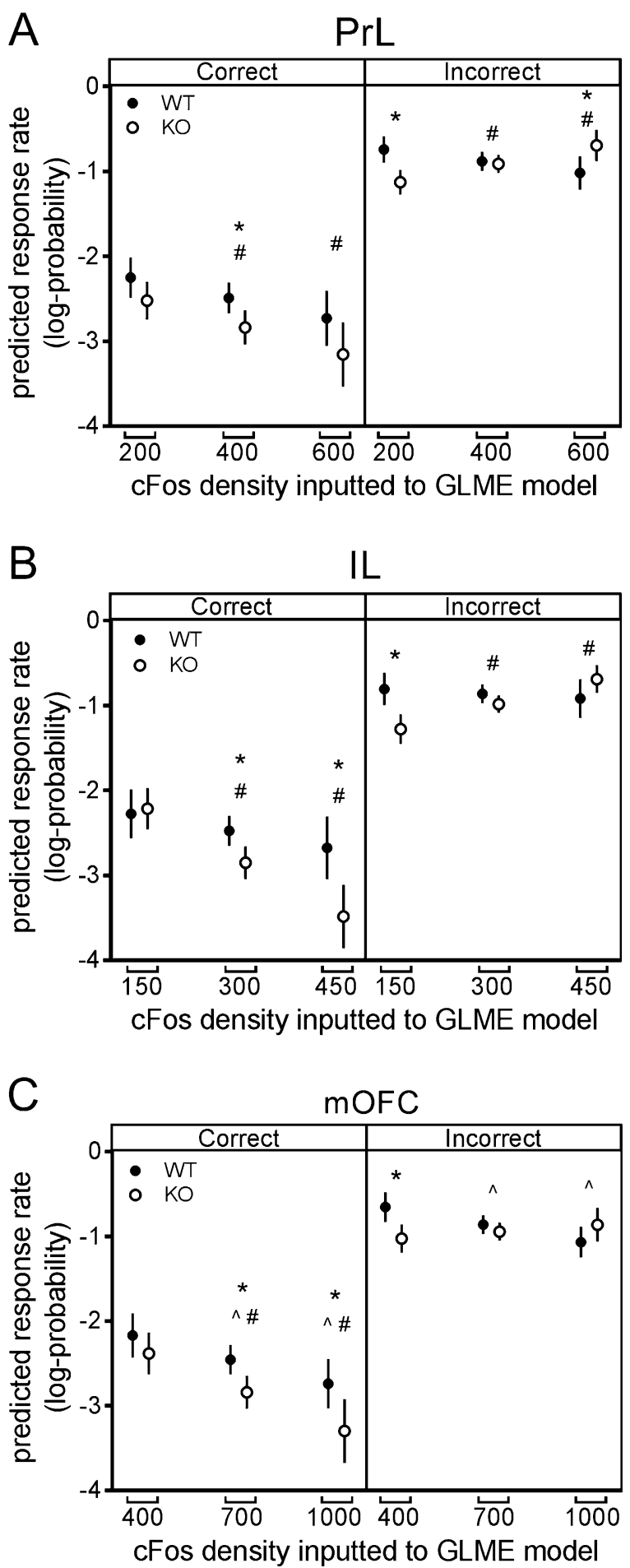

regional activation and associations with reversal performance. In Sapap3-KOs, increased neural activity in PrL and IL was associated with behavioral impairments following rule reversal (Fig. 4a, b; both higher rate of incorrect responses and lower rate of correct responses). In contrast, this association was not seen in WTs. Instead, increased neural activity in PrL, IL, mOFC, and NAc was associated with reduced response rate late in the reversal testing session in WT (Fig. 5b-f), consistent with effective engagement of networks that support extinction of the previous correct response.

Although Sapap3-KOs are genetically identical, we found that only a subset showed dramatic impairment in reversal learning.
Fig. 4 Differential associations between regional cFos expression and reversal performance in Sapap3-KOs and WTs. The relationship between regional cFos expression, genotype, and response rate on each response type was assessed using GLME analysis, which revealed altered associations between regional cFos and reversal performance in Sapap3-KOs. Data points indicate the least-squares (LS) mean of response rate $\pm 95 \%$ confidence interval (Sidak method for 12 estimates) at three cFos densities inputted to the GLME model (approximately the mean cFos density \pm 1 standard deviation, rounded to whole numbers as appropriate). This gives three points along the $x$ axis representing the influence of regional cFos density on predicted response rate. a, b In PrL and IL, increased CFos was associated with poorer reversal acquisition in Sapap3-KOs as indicated by both reduced correct responding and increased incorrect responding. c In mOFC, increased cFos was associated with lower correct responding in both WT and Sapap3-KOs; however, this effect was larger in Sapap3-KOs, resulting in significantly lower correct responding relative to WT at medium and high cFos densities (denoted by *). In contrast, increased mOFC cFos was associated with reduced perseverative incorrect responses in WT only. $n=11 \mathrm{WT}, 12 \mathrm{KO}$. * indicates difference between genotypes; \# indicates difference across cFos levels for Sapap3-KOs; $\wedge$ indicates difference across cFos levels for WTs (Tukey-adjusted comparisons for 12 estimates). mOFC medial orbitofrontal cortex, PrL prelimbic prefrontal cortex, IL infralimbic prefrontal cortex, WT wild-type controls, KO Sapap3 knockout mice, GLME generalized linear mixed effects

This model system is therefore ideal to explore correlates of OCDrelevant behavioral heterogeneity in a uniform genetic background. First, we found that $\mathrm{KO}_{\text {Rev }}$ and $\mathrm{KO}_{\text {Fail }}$ had similar levels of grooming behavior, indicating that reversal impairment was unrelated to compulsive grooming severity, and suggesting that different neural circuits may underlie these two phenotypes. Note, in contrast to the original paper describing Sapap3-KOs [20], we did not observe $100 \%$ penetrance of compulsive grooming at 4-6 months of age. However, the original study was conducted in mice on a mixed 129/Sv//C57BL/6 background strain [Dr. Guoping Feng, personal communication; also see Fig. 1a of Ref. [20]]. Our findings are consistent with another recent report using Sapap3$\mathrm{KO}$ on a $\mathrm{C} 57 \mathrm{BL} / 6$ background [37]. Second, $\mathrm{KO}_{\text {Rev }}$ and $\mathrm{KO}_{\text {Fail }}$ did not differ in their acquisition of lever pressing at the beginning of training, suggesting that reversal failure does not reflect a general learning impairment. Third, pedigree analysis of Sapap3-KOs demonstrated that most littermates were discordant for reversal learning impairment, suggesting that genetic drift within the colony or litter-related factors (e.g., parental behavior or epigenetic factors) are unlikely to contribute to the observed heterogeneity. In the absence of clear causal factors, we next turned to cFos analysis to determine whether neural activity patterns in cortico-striatal circuits could help explain this behavioral heterogeneity.

Interestingly, impaired reversal-learning performance in Sapap3-KOs was associated with increased cFos expression in the $\mathrm{mPFC}$ (PrL/IL; Fig. 4a, b). In contrast, neither correct nor incorrect responses were associated with MPFC cFos density in WT mice. Correlations between ROI cFos measurements were also stronger in Sapap3-KOs, suggesting that altered patterns of mPFC activity in KOs may have more pronounced influence over brainwide activity patterns via increased functional connectivity. Our findings suggest that heterogeneous reversal-learning performance in Sapap3-KOs may result from heterogeneity in aberrant mPFC activity, which is consistent with studies in OCD patients examining neural activity in vmPFC, the human homolog of the rodent mPFC [38]. Similar to our findings in Sapap3-KOs, vmPFC hyperactivity was recently associated with disrupted fear reversal learning in OCD patients. Specifically, vmPFC activity was elevated in OCD subjects relative to healthy controls throughout training, 

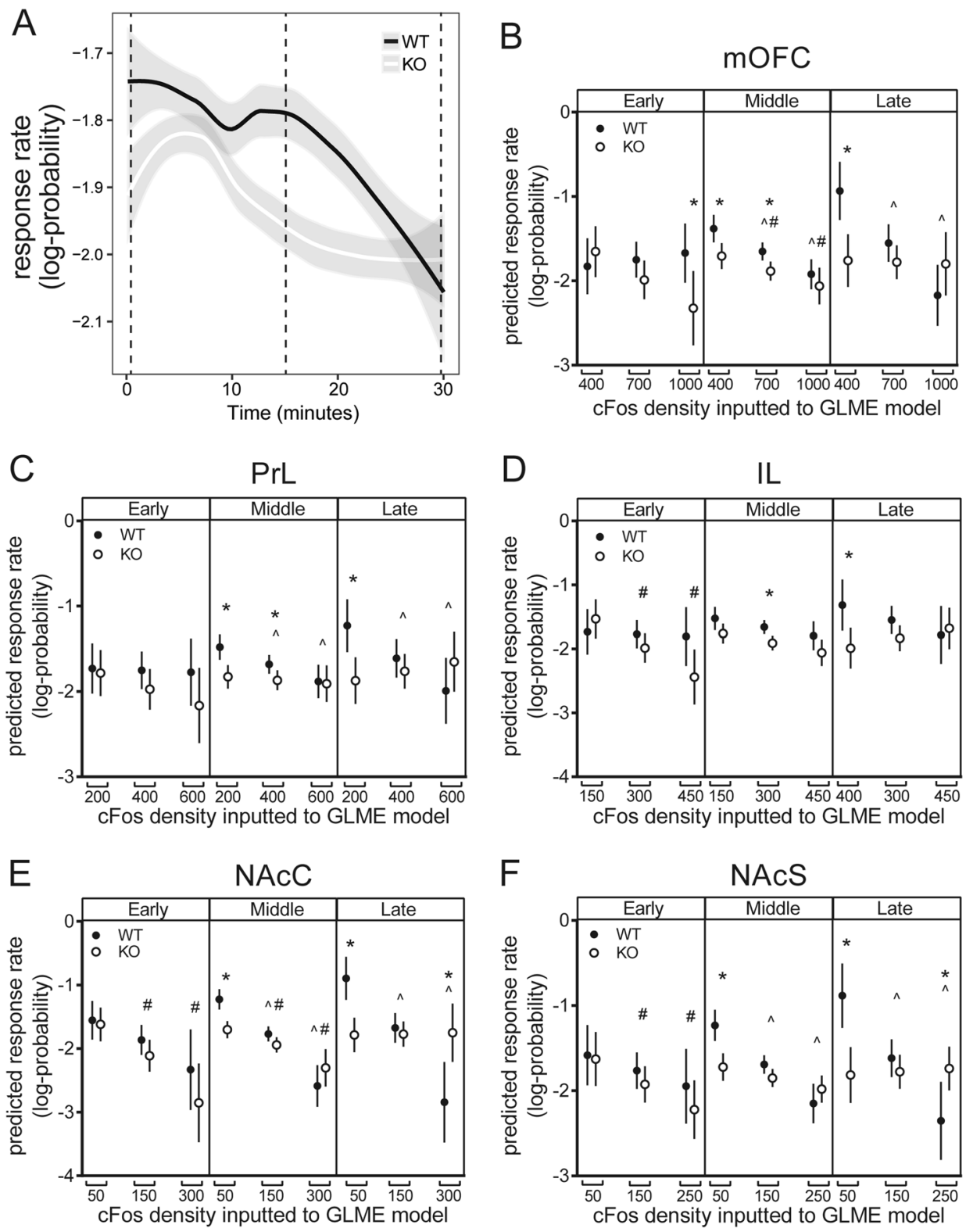

Fig. 5 Differential associations between regional cFos expression and response rate across reversal session between Sapap3-KOs and WTs. Genotype-dependent associations between regional cFos expression and response rate changes across the reversal session (for correct and incorrect levers combined) were assessed using GLME. Data points indicate the least-squares (LS) mean of response rate $\pm 95 \%$ confidence interval (Sidak method for 18 estimates) at three cFos densities (approximately the mean cFos density \pm 1 standard deviation, rounded to whole numbers as appropriate). This generates three points along the $x$ axis representing the influence of regional cFos density on response rate. a A LOESS model was used to generate smoothed response rate and error bands for behavior throughout the testing session for WT and KO mice, which are shown for illustrative purposes. This demonstrates elevated responding early after rule reversal, corresponding to the extinction burst which eventually decays as extinction initiates later in the session. The profile of responding across the session differed between the genotypes; WTs perseverated until the middle of the testing session, whereas extinction commenced earlier in KOs. The significant interaction term derived from the GLME is graphically represented in panels B-F by plotting the predicted output (response rate) of the model across a range of typical cFos densities ( mean, mean +1 standard deviation, mean -1 standard deviation) and timepoints (early, middle, and late time bin; dotted lines on a) inputted into the model. This analysis revealed genotype differences in the association between regional cFos expression and response rate changes during the session. Five ROls showed similar patterns of changes: $\mathbf{b}$ mOFC, $\mathbf{c}$ PrL, $\mathbf{d}$ ) IL, e NAcC, and $\mathbf{f}$ NAcS. Specifically, late in the reversal session, WT mice showed higher response rates than Sapap3-KOs at the lowest cFos density. Furthermore, in WTs, increased cFos expression was associated with reduced response rate, reflecting successful extinction (significant for all ROls except IL). Similar patterns of cFos-dependent modulation of response rate were observed in the middle of testing in WT mice. At this timepoint, Sapap3-KOs also showed reduced response rate with increasing cFos in NAcC and mOFC. In contrast, early in the session, WTs showed no cFos-dependent modulation of response rate, whereas Sapap3-KOs showed an association between increased cFos in NACS, NACC, and IL and reduced response rate reflecting reduced perseveration. $n=11$ WT, 12 KO. * indicates difference between genotypes; \# indicates difference across cFos levels for Sapap3-KOs; $\wedge$ indicates difference across cFos levels for WTs (Tukey-adjusted comparisons for 18 estimates). mOFC medial orbitofrontal cortex, PrL prelimbic prefrontal cortex, IL infralimbic prefrontal cortex, NAcS nucleus accumbens shell, NAcC nucleus accumbens core, WT wild-type controls, KO Sapap3 knockout mice, GLME generalized linear mixed effects 
and did not show the appropriate modulation required to update the reversed contingency [13]. Impaired recruitment and modulation of vmPFC activity in OCD patients has also been reported during fear extinction recall [14], task switching [15], and a flanker task (during errors) [16], suggesting that vmPFC dysfunction in OCD patients may disrupt flexible learning of both rewarding and aversive contingencies. vmPFC hyperactivity is also associated with symptom-provoked anxiety in OCD patients with hoarding [8], and mPFC has recently been implicated in compulsive checking in a rodent model [39]. Together with our data, these findings suggest that more work is warranted investigating vmPFC contributions to OCD symptoms in the context of flexible learning. Interestingly, reversal-learning performance deficits have been inconsistent in studies of OCD patients [11, 12,32,33]; our findings suggest that these inconsistencies may reflect heterogeneity in neuropathology between study subject populations. OFC dysfunction has been demonstrated in OCD patients during reversal learning independent of reversal performance [11, 12]; however, well-powered clinical studies with baseline and reversal-learningrelated neuroimaging data have not been performed to address whether heterogeneous task performance is associated with distinct neural correlates. Based on our current findings, we would predict that elevated vmPFC activity is associated with severity of reversal-learning impairments in OCD patients.

Our findings in WT mice are consistent with studies demonstrating that mPFC lesion and pharmacological inactivation have no significant effect on reversal learning in normal rodents [34, 40, 41]. However, these same interventions disrupt cognitive flexibility in more complex set-shifting tasks $[40,41]$, suggesting a role for mPFC during greater cognitive load [42]. Consistent with this idea, rule-responsive neurons have been identified in the MPFC using in vivo electrophysiology not only during set shifting [43-45], but also during reversal learning and stable performance of ruleguided decision-making [43]. Importantly, the proportion of responsive cells is increased during set shifting relative to reversal learning and stable performance, which likely mediates the critical role of the mPFC in this behavior [43]. Although the potential function of rule-responsive mPFC neurons during reversal learning is currently unknown, findings from a recent study suggest that they may impact reversal performance. Using a spatially restricted pharmacogenetic approach, the authors demonstrated that acute suppression of PrL activity significantly improves reversal learning [46]. This supports our finding that increased mPFC cFos is associated with impaired reversal learning in Sapap3-KOs, and suggests that aberrant activity in a subpopulation of PrL neurons could interfere with reversal learning, potentially by encoding the old rule. It is also currently unclear whether reversal-learningassociated recruitment of mPFC activity (as quantified using cFos) is state-dependent (i.e., dependent on performance in both $\mathrm{KO}_{\mathrm{Rev}}$ and $\mathrm{KO}_{\text {Fail }}$ ) or a stable trait (i.e., inherently and stably different in $\mathrm{KO}_{\text {Rev }}$ and $\left.\mathrm{KO}_{\text {Fail }}\right)$. In the data presented in Fig. 2a, 8/15 mice in the $\mathrm{KO}_{\mathrm{Rev}}$ group did not reach reversal criteria on the first day of training. If mPFC activity during reversal is state-dependent, we would predict that these mice would show mPFC hyperactivity on the first day of training because their reversal performance is poor; however, on subsequent days, we would expect a decline in MPFC activity, permitting acquisition of the new rule. Further investigation of mPFC involvement in reversal learning is warranted, particularly in the context of impaired performance in Sapap3$\mathrm{KOs}$, where longitudinal in vivo measurement of neural activity during reversal learning will be important to test these predictions.

The combined rate of correct and incorrect responses typically decays across the first day of reversal (Fig. 5a), as the mouse begins to undergo extinction of the previously correct response (Figure S8D). Although cFos measurements reflect the sum of activity across the entire session, we were able to use GLME analysis to identify genotype-dependent associations between
cFos densities inputted into the model and predicted response rates at different timepoints during the session. These changes in associations across the session may reflect differential engagement of extinction, reward seeking, and value comparison processes subserved by these areas at different points during reversal learning. Typically, the IL-NAcS circuit is most strongly implicated in the acquisition and expression of extinction $[47,48]$, whereas the PrL-NACC is more implicated in the expression of reward-seeking behavior [49,50]. However, in the context of reversal learning, PrL-NACC may help to invigorate exploratory reward-seeking behavior that supports acquisition of the new correct response and decreases perseverative responding. In addition, the mOFC plays a critical role in value comparisons [51] and helps guide flexible decision-making based on changing outcome values (e.g., following outcome devaluation) [34, 52]. Therefore, increased mOFC activity may support extinction of the previously correct response through improved representation of the new value associated with that response following reversal. Findings from the GLME analysis were consistent with these ideas, by demonstrating that elevated neural activity in PFC (PrL, IL, and mOFC; Fig. 5b-d) and NAc (both core and shell; Fig. 5e, f) supports extinction late on the first day of reversal in WTs. These associations were absent late in training in Sapap3-KOs, although some overlapping ROls were associated with reduced response rate early and mid-way through training in KOs. These changes are consistent with an altered response profile in $\mathrm{KO}$, including attenuated peak of "extinction burst", suggesting that earlier recruitment of extinction-associated networks may contribute to these changes in the profile of responding in Sapap3-KOs [47-49].

It is important to recognize the limitations of static cFos measurements, which lack temporal resolution to precisely link neural activity to specific behaviors, or to describe dynamic changes in activity that may underlie behavior. Based on previous studies demonstrating that cFos expression peaks $60-120 \mathrm{~min}$ following neural activity, and is relatively stable across this period [53], our assumption is that neural activity at the start $(120 \mathrm{~min}$ prior to tissue collection) and end (up to $90 \mathrm{~min}$ prior to tissue collection) of testing contributed equally to cFos-positive cell counts. However, if neural activity led to greater cFos expression at particular times during the session, this could complicate our interpretation of genotype differences, due to the differential time course of learning in WTs and KOs leading to increased frequency of early session termination in WTs. Furthermore, correct responding in this paradigm is proportional to correct-response contingent rewards received in the session $(\sim 2: 1$ on VR2 schedule), and it is therefore possible that significant associations between $\mathrm{ROI}$ cFos and correct responding are influenced by receipt of contingent rewards rather than performance of correct responses. Nonetheless, by surveying 10 ROls simultaneously and leveraging GLME analysis, these quantitative cFos studies have generated novel hypotheses regarding neural mechanisms regulating OCD-associated cognitive flexibility. Future studies using more temporally precise measurements of neural activity in vivo will be important to address the limitations of these experiments and test these new hypotheses. It is also important to note that Sapap3-KOs are less active than WTs, which could confound interpretation of reversal-learning findings. However, it is unlikely that our observed impairments in reversal learning are a consequence of reduced activity, because KOs show similar levels of correct responding during discrimination training (Fig. 1b), suggesting similar ability to engage in the task. Nevertheless, this is an important consideration for researchers using this transgenic model, as cognitive tasks with higher motor demands may be susceptible to this confound.

In conclusion, these studies are among the first to describe impairments in OCD-relevant cognitive flexibility in Sapap3-KOs [29]. Despite the limitations of cFos as an indirect measure of neural activation, our findings suggest that severity of reversal-learning 
deficits is related to hyperactivity in the MPFC. Future studies using this model may also help to identify specific neural mechanisms underlying mPFC hyperactivity and disruption of cognitive flexibility. This could ultimately guide the development of novel neuromodulatory treatments that could potentially both decrease OCD symptoms and facilitate vocational and social functioning.

\section{FUNDING AND DISCLOSURE}

These studies were supported by BRAINS R01 MH104255, McKnight Neuroscience Scholar Award, MQ Fellows Award, Burroughs Wellcome Fund CAMS Award, Klingenstein Fellowship in the Neurosciences (SEA), and American Australian Association Sir Keith Murdoch Fellowship (EEM).

\section{ACKNOWLEDGEMENTS}

We would like to thank Mr Junyue Shen for assistance with operant testing, Ms Anna Winner for assistance with compulsive grooming analysis, and the Ahmari lab for helpful feedback on the projects included in the paper.

\section{ADDITIONAL INFORMATION}

Supplementary Information accompanies this paper at (https://doi.org/10.1038/ s41386-018-0307-2)

Competing interests: All authors have no biomedical financial interests or potentia conflicts of interest to report.

Publisher's note: Springer Nature remains neutral with regard to jurisdictional claims in published maps and institutional affiliations.

\section{REFERENCES}

1. Kessler RC, Chiu WT, Demler O, Merikangas KR, Walters EE. Prevalence, severity, and comorbidity of 12-month DSM-IV disorders in the national comorbidity survey replication. Arch Gen Psychiatry. 2005;62:617-27. https://doi.org/10.1001/ archpsyc.62.6.617.

2. Koran LM. Quality of life in obsessive-compulsive disorder. Psychiatr Clin North Am. 2000;23:509-17.

3. Del Casale A, Kotzalidis GD, Rapinesi C, Serata D, Ambrosi E, Simonetti A, et al Functional neuroimaging in obsessive-compulsive disorder. Neuropsychobiology. 2011;64:61-85. https://doi.org/10.1159/000325223.

4. Manning EE, Ahmari SE. How can preclinical mouse models be used to gain insight into prefrontal cortex dysfunction in obsessive-compulsive disorder? Brain Neurosci Adv. 2018;2:2398212818783896 https://doi.org/10.1177/ 2398212818783896

5. Baxter LR Jr., Phelps ME, Mazziotta JC, Guze BH, Schwartz JM, Selin CE. Local cerebral glucose metabolic rates in obsessive-compulsive disorder. A comparison with rates in unipolar depression and in normal controls. Arch Gen Psychiatry. 1987;44:211-8.

6. Rauch SL, Jenike MA, Alpert NM, Baer L, Breiter HC, Savage CR, et al. Regional cerebral blood flow measured during symptom provocation in obsessivecompulsive disorder using oxygen 15-labeled carbon dioxide and positron emission tomography. Arch Gen Psychiatry. 1994;51:62-70.

7. Breiter HC, Rauch SL, Kwong KK, Baker JR, Weisskoff RM, Kennedy DN, et al. Functional magnetic resonance imaging of symptom provocation in obsessivecompulsive disorder. Arch Gen Psychiatry. 1996;53:595-606.

8. An SK, Mataix-Cols D, Lawrence NS, Wooderson S, Giampietro V, Speckens A, et al. To discard or not to discard: the neural basis of hoarding symptoms in obsessivecompulsive disorder. Mol Psychiatry. 2009;14:318-31. https://doi.org/10.1038/sj. mp.4002129.

9. Benkelfat C, Nordahl TE, Semple WE, King AC, Murphy DL, Cohen RM. Local cerebral glucose metabolic rates in obsessive-compulsive disorder. Patients treated with clomipramine. Arch Gen Psychiatry. 1990;47:840-8.

10. van der Straten $A L$, Denys $D$, van Wingen GA. Impact of treatment on resting cerebral blood flow and metabolism in obsessive compulsive disorder: a metaanalysis. Sci Rep. 2017;7:17464 https://doi.org/10.1038/s41598-017-17593-7.

11. Remijnse PL, Nielen MM, van Balkom AJ, Cath DC, van Oppen $P$, Uylings $H B$, et al. Reduced orbitofrontal-striatal activity on a reversal learning task in obsessivecompulsive disorder. Arch Gen Psychiatry. 2006;63:1225-36. https://doi.org/ 10.1001/archpsyc.63.11.1225.
12. Chamberlain SR, Menzies L, Hampshire A, Suckling J, Fineberg NA, del Campo N, et al. Orbitofrontal dysfunction in patients with obsessive-compulsive disorder and their unaffected relatives. Science. 2008;321:421-2. https://doi.org/10.1126/ science. 1154433.

13. Apergis-Schoute AM, Gillan CM, Fineberg NA, Fernandez-Egea E, Sahakian BJ, Robbins TW. Neural basis of impaired safety signaling in obsessive compulsive disorder. Proceedings of the National Academy of Sciences of the United States of America. 2017;114:3216-21. https://doi.org/10.1073/pnas.1609194114.

14. Milad MR, Furtak SC, Greenberg JL, Keshaviah A, Im JJ, Falkenstein MJ, et al Deficits in conditioned fear extinction in obsessive-compulsive disorder and neurobiological changes in the fear circuit. JAMA Psychiatry. 2013;70:608-18. https://doi.org/10.1001/jamapsychiatry.2013.914. quiz 554.

15. Gu BM, Park JY, Kang DH, Lee SJ, Yoo SY, Jo HJ, et al. Neural correlates of cognitive inflexibility during task-switching in obsessive-compulsive disorder. Brain: a J Neurol. 2008;131:155-64. https://doi.org/10.1093/brain/awm277.

16. Stern ER, Welsh RC, Fitzgerald KD, Gehring WJ, Lister JJ, Himle JA, et al. Hyperactive error responses and altered connectivity in ventromedial and frontoinsular cortices in obsessive-compulsive disorder. Biol Psychiatry. 2011;69:583-91. https://doi.org/10.1016/j.biopsych.2010.09.048.

17. Vaghi $M M$, Hampshire A, Fineberg NA, Kaser M, Bruhl AB, Sahakian BJ, et al. Hypoactivation and dysconnectivity of a frontostriatal circuit during goaldirected planning as an endophenotype for obsessive-compulsive disorder. Biol Psychiatry Cogn Neurosci Neuroimaging. 2017;2:655-63. https://doi.org/10.1016/ j.bpsc.2017.05.005.

18. Harrison BJ, Soriano-Mas C, Pujol J, Ortiz H, Lopez-Sola M, Hernandez-Ribas R, et al. Altered corticostriatal functional connectivity in obsessive-compulsive disorder. Arch Gen Psychiatry. 2009;66:1189-200. https://doi.org/10.1001/ archgenpsychiatry.2009.152.

19. Posner J, Marsh R, Maia TV, Peterson BS, Gruber A, Simpson HB. Reduced functional connectivity within the limbic cortico-striato-thalamo-cortical loop in unmedicated adults with obsessive-compulsive disorder. Hum Brain Mapp. 2014;35:2852-60. https://doi.org/10.1002/hbm.22371

20. Welch JM, Lu J, Rodriguiz RM, Trotta NC, Peca J, Ding JD, et al. Cortico-striatal synaptic defects and OCD-like behaviours in Sapap3-mutant mice. Nature. 2007;448:894-900. https://doi.org/10.1038/nature06104.

21. Burguiere $E$, Monteiro $P$, Feng G, Graybiel AM. Optogenetic stimulation of lateral orbitofronto-striatal pathway suppresses compulsive behaviors. Science. 2013;340:1243-6. https://doi.org/10.1126/science.1232380.

22. Shmelkov SV, Hormigo A, Jing D, Proenca CC, Bath KG, Milde T, et al. Slitrk5 deficiency impairs corticostriatal circuitry and leads to obsessive-compulsive-like behaviors in mice. Nat Med. 2010;16:598-602. https://doi.org/10.1038/nm.2125.

23. Nagarajan $\mathrm{N}$, Jones BW, West PJ, Marc RE, Capecchi MR. Corticostriatal circuit defects in Hoxb8 mutant mice. Mol Psychiatry. 2017. https://doi.org/10.1038/ mp.2017.180.

24. Ullrich M, Weber M, Post AM, Popp S, Grein J, Zechner M, et al. OCD-like behavior is caused by dysfunction of thalamo-amygdala circuits and upregulated TrkB/ ERK-MAPK signaling as a result of SPRED2 deficiency. Mol Psychiatry. 2017 https://doi.org/10.1038/mp.2016.232.

25. Rapanelli M, Frick L, Bito H, Pittenger C. Histamine modulation of the basal ganglia circuitry in the development of pathological grooming. Proc Natl Acad Sci USA. 2017;114:6599-604. https://doi.org/10.1073/pnas.1704547114.

26. Kalueff AV, Stewart AM, Song C, Berridge KC, Graybiel AM, Fentress JC. Neurobiology of rodent self-grooming and its value for translational neuroscience. Nat Rev Neurosci. 2016;17:45-59. https://doi.org/10.1038/nrn.2015.8.

27. Ahmari SE, Spellman T, Douglass NL, Kheirbek MA, Simpson HB, Deisseroth $\mathrm{K}$ et al. Repeated cortico-striatal stimulation generates persistent OCD-like behavior. Science. 2013:340:1234-9. https://doi.org/10.1126/science.1234733.

28. Ade KK, Wan Y, Hamann HC, O'Hare JK, Guo W, Quian A, et al. Increased metabotropic glutamate receptor 5 signaling underlies obsessive-compulsive disorder-like behavioral and striatal circuit abnormalities in mice. Biol Psychiatry. 2016;80:522-33. https://doi.org/10.1016/j.biopsych.2016.04.023.

29. van den Boom BJG, Mooij AH, Misevičiūtè I, Denys D, Willuhn I. Behavioral flexibility in an OCD mouse model: Impaired Pavlovian reversal learning in SAPAP3 mutants. bioRxiv. 2018. https://doi.org/10.1101/435172.

30. Zuchner S, Wendland JR, Ashley-Koch AE, Collins AL, Tran-Viet KN, Quinn K, et al. Multiple rare SAPAP3 missense variants in trichotillomania and OCD. Mol Psychiatry. 2009;14:6-9. https://doi.org/10.1038/mp.2008.83.

31. Mattheisen M, Samuels JF, Wang Y, Greenberg BD, Fyer AJ, McCracken JT, et al. Genome-wide association study in obsessive-compulsive disorder: results from the OCGAS. Mol Psychiatry. 2015;20:337-44. https://doi.org/10.1038/mp.2014.43.

32. Gottwald J, de Wit S, Apergis-Schoute AM, Morein-Zamir S, Kaser M, Cormack F et al. Impaired cognitive plasticity and goal-directed control in adolescent obsessive-compulsive disorder. Psychological Med. 2018:1-9. https://doi.org/ $10.1017 /$ S0033291717003464 
33. Valerius G, Lumpp A, Kuelz AK, Freyer T, Voderholzer U. Reversal learning as a neuropsychological indicator for the neuropathology of obsessive compulsive disorder? A behavioral study. J Neuropsychiatry Clin Neurosci. 2008;20:210-8. https://doi.org/10.1176/appi.neuropsych.20.2.210. 10.1176/jnp.2008.20.2.210.

34. Gourley SL, Lee AS, Howell JL, Pittenger C, Taylor JR. Dissociable regulation of instrumental action within mouse prefrontal cortex. Eur J Neurosci. 2010;32:1726-34. https://doi.org/10.1111/j.1460-9568.2010.07438.x.

35. Flagel SB, Cameron CM, Pickup KN, Watson SJ, Akil $H$, Robinson TE. A food predictive cue must be attributed with incentive salience for it to induce c-fos mRNA expression in cortico-striatal-thalamic brain regions. Neuroscience. 2011;196:80-96. https://doi.org/10.1016/j.neuroscience.2011.09.004.

36. Lerman DC, Iwata BA. Prevalence of the extinction burst and its attenuation during treatment. J Appl Behav Anal. 1995;28:93-4.

37. Mintzopoulos D, Gillis TE, Robertson HR, Dalia T, Feng G, Rauch SL, et al. Striatal magnetic resonance spectroscopy abnormalities in young adult SAPAP3 knockout mice. Biol Psychiatry Cogn Neurosci Neuroimaging. 2016;1:39-48. https://doi. org/10.1016/j.bpsc.2015.10.001.

38. Wallis CU, Cardinal RN, Alexander L, Roberts AC, Clarke HF. Opposing roles of primate areas 25 and 32 and their putative rodent homologs in the regulation of negative emotion. Proceedings of the National Academy of Sciences of the United States of America. 2017;114:E4075-E84. https://doi.org/10.1073/ pnas.1620115114.

39. d'Angelo C, Eagle DM, Coman CM, Robbins TW. Role of the medial prefrontal cortex and nucleus accumbens in an operant model of checking behaviour and uncertainty. Brain Neurosci Adv. 2017;1:2398212817733403 https://doi.org/ 10.1177/2398212817733403.

40. Bissonette GB, Martins GJ, Franz TM, Harper ES, Schoenbaum G, Powell EM. Double dissociation of the effects of medial and orbital prefrontal cortical lesions on attentional and affective shifts in mice. J Neurosci: Off J Soc Neurosci. 2008;28:11124-30. https://doi.org/10.1523/JNEUROSCI.2820-08.2008.

41. Floresco SB, Block AE, Tse MT. Inactivation of the medial prefrontal cortex of the rat impairs strategy set-shifting, but not reversal learning, using a novel, automated procedure. Behav Brain Res. 2008;190:85-96. https://doi.org/10.1016/j. bbr.2008.02.008.

42. Izquierdo A, Brigman JL, Radke AK, Rudebeck $\mathrm{PH}$, Holmes $\mathrm{A}$. The neural basis of reversal learning: An updated perspective. Neuroscience. 2017;345:12-26. https:// doi.org/10.1016/j.neuroscience.2016.03.021.
43. Rich EL, Shapiro M. Rat prefrontal cortical neurons selectively code strategy switches. J Neurosci: Off J Soc Neurosci. 2009;29:7208-19. https://doi.org/ 10.1523/JNEUROSCI.6068-08.2009.

44. Bissonette GB, Roesch MR. Neural correlates of rules and conflict in medial prefrontal cortex during decision and feedback epochs. Front Behav Neurosci. 2015;9:266. https://doi.org/10.3389/fnbeh.2015.00266.

45. Durstewitz D, Vittoz NM, Floresco SB, Seamans JK. Abrupt transitions between prefrontal neural ensemble states accompany behavioral transitions during rule learning. Neuron. 2010;66:438-48. https://doi.org/10.1016/j.neuron.2010.03.029;

46. Mukherjee $A$, Caroni P. Infralimbic cortex is required for learning alternatives to prelimbic promoted associations through reciprocal connectivity. Nat Commun. 2018;9:2727. https://doi.org/10.1038/s41467-018-05318-x.

47. Peters J, LaLumiere RT, Kalivas PW. Infralimbic prefrontal cortex is responsible for inhibiting cocaine seeking in extinguished rats. J Neurosci: Off J Soc Neurosci. 2008;28:6046-53. https://doi.org/10.1523/JNEUROSCI.1045-08.2008.

48. Ghazizadeh A, Ambroggi F, Odean N, Fields HL. Prefrontal cortex mediates extinction of responding by two distinct neural mechanisms in accumbens shell. J Neurosci: Off J Soc Neurosci. 2012;32:726-37. https://doi.org/10.1523/ JNEUROSCI.3891-11.2012.

49. Stefanik MT, Kupchik YM, Kalivas PW. Optogenetic inhibition of cortical afferents in the nucleus accumbens simultaneously prevents cue-induced transient synaptic potentiation and cocaine-seeking behavior. Brain Struct Funct. 2016;221:1681-9. https://doi.org/10.1007/s00429-015-0997-8.

50. Gourley SL, Taylor JR. Going and stopping: Dichotomies in behavioral control by the prefrontal cortex. Nat Neurosci. 2016;19:656-64. https://doi.org/10.1038/ nn.4275.

51. Noonan MP, Walton ME, Behrens TE, Sallet J, Buckley MJ, Rushworth MF. Separate value comparison and learning mechanisms in macaque medial and lateral orbitofrontal cortex. Proceedings of the National Academy of Sciences of the United States of America. 2010;107:20547-52. https://doi.org/10.1073/ pnas.1012246107.

52. Gourley SL, Zimmermann KS, Allen AG, Taylor JR. The Medial Orbitofrontal Cortex Regulates Sensitivity to Outcome Value. J Neurosci: Off J Soc Neurosci. 2016;36:4600-13. https://doi.org/10.1523/JNEUROSCI.4253-15.2016.

53. Barros VN, Mundim M, Galindo LT, Bittencourt S, Porcionatto M, Mello LE. The pattern of c-Fos expression and its refractory period in the brain of rats and monkeys. Front Cell Neurosci. 2015;9:72. https://doi.org/10.3389/fncel.2015.00072. 